\title{
ROLE OF MULTIDETECTOR COMPUTED TOMOGRAPHY INDIAGNOSIS OF SMALLBOWEL DISEASES
}

\author{
By

\begin{abstract}
Sarah El-Sayed Gouda Mohamed, Mohamed Farouk Aggag and AbdUllah Ahmed
\end{abstract} \\ Radio diagnosis department, Faculty of Medicine, Al-Azhar University, Cairo, Egypt \\ Corresponding author: Sarah El-Sayed Gouda Mohamed
}

Mobile: 01095348147, E-mail: sosoo.sarah@yahoo.com

\begin{abstract}
Background: Multi-detector computed tomography (MDCT) helps in evaluation of small bowel diseases such as small bowel wall lesions especially differentiation of benign and malignant lesions, Small bowel obstruction (SBO), Mesenteric arterial thrombosis, mesenteric venous thrombosis, or no occlusive mesenteric ischemia, chronic mesenteric ischemia the diagnosis of them is made by MDCT.

Objective: To assess the efficacy of MDCT in diagnosis and evaluation of various small bowel diseases such as Meckel's diverticulum, small bowel obstruction, inflammatory bowel diseases, and bowel Ischemia.

Patients and methods: Study was done at the Department of Radiology at Belbis General Hospital through a period from February 2020 to November 2020.It included 30 patients: 22 were malesand 8 were females, with acute and recurrent abdominal pain, vomiting and distention. Their ages ranged between $35-81$ years with a mean age of 59.35 years old.

Results: Our results showed sixteen patients had vascular disease. Four patients had intestinal obstruction, six patients had inflammatory disease, three patients had neoplastic disease, and one patient showed mesenteric panniculitis.

Conclusion: MDCT allowed detection of mural enhancement after intravenous contrast.Combination with positive oral contrast was better used in neoplastic cases to outline the mass and differentiate it from the surrounding is Odense structures. It is also better used in cases with incomplete intestinal obstruction to confirm passage of contrast distal to the site of obstruction.
\end{abstract}

Keywords: MDCT; Abdominal pain; Intestinal obstruction, Bowel wall thickening, vascular abnormalities.

Disclosure: Authors declare no conflict of interest.

\section{INTRODUCTION}

Small bowel obstruction (SBO) is a common cause of abdominal pain, accounting for $4 \%$ of emergency department admissions and $20 \%$ of emergency surgical procedures (1-3). Currently, computed tomography (CT) is the preferred imaging technique, as it can be used to diagnose the condition, identify the cause and site of obstruction, and detect ischemia, a complication seen in about $10 \%$ of patients and associated with a $30 \%$ mortality rate (Chuong et al., 2016).

Imaging has always been critical in the evaluation of the small bowel, because of 
poor accessibility with conventional endoscopic techniques, and also new endoscopic imaging methods i.e. capsule endoscopy and double-balloon and push enteroscopy have not completely solved the diagnostic problem in many clinical situations involving the small bowel, and they are still considered complimentary. Multi-detector computed tomography (MDCT) helps in evaluation of small bowel (Rengoet al., 2017).

Multi-detector computed tomography has led to vast improvement in depiction and characterization of small bowel wall lesions especially differentiation of benign and malignant lesions. Early detection of the neoplasm of small bowel is a highly desirable but a very challenging task for the clinicians as well as radiologists (Postemaet al., 2011).

Acute mesenteric ischemia (AMI) is a rare life-threatening condition, the mortality rate for AMI is as high as $50 \%$ $69 \%$.AMI is caused by mesenteric arterial embolism, Mesenteric arterial thrombosis, mesenteric venous thrombosis, or no occlusive mesenteric ischemia. The diagnosis of chronic mesenteric ischemia is made at multidetector computed tomography (Kanasaki et al., 2018).

The aim of the present work was to assess the efficacy of MDCT in diagnosis and evaluation of various small bowel diseases such as Meckel's diverticulum, small bowel obstruction, inflammatory bowel diseases, and bowel ischemia.

\section{PATIENTS AND METHODS}

A written informed consent was taken from every participant after proper explanation of the study.
This study was carried out on thirty patients with suspected small bowel diseases at Belbis General Hospital at the period of February 2020 to November 2020, 22 males and 8 females their ages ranged between 33 and 81 with Mean \pm SD52.2 \pm 11.90 .

Inclusion criteria: Patients with suspected intestinal obstruction, acute abdominal pain with history of previous mesenteric ischemia, intermittent cramping post-prandial abdominal pain, and weight loss due to food fear and attacks of melena together with history of recurrent episodes of melena.

The present study used IV contrast medium (about 70-100ml) of non-ionic contrast medium (iopromide $300 \mathrm{mgI} / \mathrm{ml}$ ) according to the body built $(1.5 \mathrm{ml} / \mathrm{kg}$ body weight) followed by $30 \mathrm{ml}$ of saline solution was given by infusion pump at rate $3-5 \mathrm{ml} / \mathrm{sec}$ by mono-phasic technique, beginning the acquisition during the portal (enteric) phase 40-55 seconds after the initiation of IV contrast injection using the scan delay technique.

Exclusion criteria: Pregnant female patient, severe allergic reaction due to IV contrast media, and terminal liver or renal failure.

\section{MDCT Examination:}

Prior to examination, the patients were instructed to fast for not less than eight hours before examination. A large bore (18-gauge) intravenous line was placed in the ante-cubital fossa. Neutral oral contrast medium solution was given, the patients ingested $1500 \mathrm{cc}(1000 \mathrm{cc}$ of water and $500 \mathrm{cc}$ of mannitol) over $60 \mathrm{~min}$ in a regular manner (250 cc every 10 min).No oral contrast was given to the 
patients who will be suspected to have acute intestinal obstruction. The patients were instructed to follow the breath hold technique. Contrast medium (about $70-$ $100 \mathrm{ml}$ ) of non-ionic contrast medium iopromide $300 \mathrm{mg} \mathrm{I} / \mathrm{ml}$ according to the body weight $(1.5 \mathrm{ml} / \mathrm{kg})$ followed by 30 $\mathrm{ml}$ of saline solution were given intravenously by infusion pump at a rate of 3-5 $\mathrm{ml} / \mathrm{second}$ by mono-phasic technique. Pre-contrast scan was done in all patients. Single phase scanning during the portal phase (enteric phase) was used; images were obtained 40 -50 seconds after initiation of IV contrast injection. Biphasic scanning (Mesenteric angiography) was used in patients who suspected to have bowel ischemia either due to mesenteric vascular disease or mechanical intestinal obstruction. Images were obtained during both arterial and portal phases (usually 20 and 55-60 seconds after initiation of IV contrast injection respectively). Axial $3 \mathrm{~mm}$ sections and 3 mm thick coronal and sagittal multi-planar reformatted images at $3 \mathrm{~mm}$ intervals were generated encompassing the entire bowel.

Statistical analysis: The clinical data, laboratory investigations and MDCT measurements are collected using Microsoft Excel software and then analyzed using Statistical Package for the Social Sciences (SPSS version 25).Method of presenting data and the used statistical test was Chi-squared test, $\mathrm{p}<0.05$ was considered statistically, significant.

\section{RESULTS}

Most frequent complains among the studied group were abdominal pain, diarrhea, vomiting and loss of weight
$(93.3 \%, \quad 40 \%, \quad 36.7 \% \quad \& \quad 26.7 \%$ respectively) (Table 1).

Table (1): Complains among the studied cases

\begin{tabular}{|l|c|c|}
\hline \multirow{2}{*}{ Complains } & \multicolumn{2}{|c|}{$(\mathbf{n}=\mathbf{3 0})$} \\
\cline { 2 - 3 } & No & \% \\
\hline Abdominal pain & 28 & 93.3 \\
Diarrhea & 12 & 40 \\
Vomiting & 11 & 36.7 \\
Loss of weight & 8 & 26.7 \\
Distension & 4 & 13.3 \\
Epigastria pain & 2 & 6.7 \\
Melena & 2 & 6.7 \\
Failed to pass stool & 2 & 6.7 \\
Dyspepsia & 1 & 3.3 \\
Fatigue & 1 & 3.3 \\
\hline
\end{tabular}

Only $13.3 \%$ of the studied cases showed normal intestinal CT. Regarding most common findings among abnormal cases they were bowel wall thickness and mesenteric congestion $(33.3 \%$ \& $23.3 \%$ respectively) (Table 2). 
Table (2): Intestinal abnormalities by CT among the studied cases

\begin{tabular}{|l|c|c|}
\hline \multirow{2}{*}{ CT } & \multicolumn{2}{|c|}{ (n=30) } \\
\cline { 2 - 3 } Normal & No & $\%$ \\
Abnormal & 4 & 13.3 \\
\hline Bowel wall thickness & 26 & 86.7 \\
Mesenteric congestion & 10 & 33.3 \\
Luminal dilation & 7 & 23.3 \\
Pyloric wall thickening & 4 & 13.3 \\
Free fluid collection & 4 & 13.3 \\
Intestinal obstruction & 4 & 13.3 \\
Intestinal pneomtosis & 4 & 13.3 \\
Lack of enhancement & 3 & 10 \\
Enhancement & 4 & 13.3 \\
Gastric wall thickening & 26 & 86.7 \\
Duodenal wall thickening & 2 & 6.7 \\
Ileum wall thickening & 2 & 6.7 \\
Cecum wall thickening & 2 & 6.7 \\
Jujenal wall thickening & 2 & 6.7 \\
Transverse colon wall thickening & 1 & 3.3 \\
Internal hernia containsjeujinal lobes & 1 & 3.3 \\
Enteroentric fistula & 1 & 3.3 \\
Malrotated bowel, polysplenia syndrome & 1 & 3.3 \\
Mesenteric panniculitis & 1 & 3.3 \\
\hline
\end{tabular}

There were $83.3 \%$ of the studied cases had normal mesenteric vein CT. All abnormal cases $(16.7 \%)$ had superior mesenteric vein thrombosis in $6.7 \%$ of them extended to portal vein and in 3.3\% associated with inferior mesenteric vein thrombosis and splenic vein thrombosis (Table 3).

Table (3): Mesenteric venous abnormalities by CT among the studied cases

\begin{tabular}{|l|c|c|}
\hline \multirow{2}{*}{ CT } & \multicolumn{2}{|c|}{$(\mathbf{n = 3 0})$} \\
\cline { 2 - 3 } & No & $\%$ \\
\hline Normal & 25 & 83.3 \\
Abnormal & 5 & 16.7 \\
\hline Superior mesenteric vein thrombosis & 3 & 10 \\
SMV thrombosis extended to portal vein & 2 & 6.7 \\
Inferior mesenteric vein thrombosis & 1 & 3.3 \\
Splenic vein thrombosis & 1 & 3.3 \\
\hline
\end{tabular}

There were $73.3 \%$ of the studied cases had normal aortic artery CT. $16.7 \%$ had calcified atherosclerotic plaques, $6.7 \%$ had thoraco-abdominal aortic aneurysm and finally $3.3 \%$ had partially thrombosed large abdominal aortic aneurysm (Table 4). 
Table (4): Aortic artery abnormalities by CT among the studied cases

\begin{tabular}{|l|c|c|}
\hline \multirow{2}{*}{ CT } & \multicolumn{2}{|c|}{$(\mathbf{n}=30)$} \\
\cline { 2 - 3 } & No & $\%$ \\
\hline Normal & 22 & 73.3 \\
Abnormal & $\mathbf{8}$ & 26.7 \\
\hline Calcified atherosclerotic plaques & 5 & 16.7 \\
Partially thrombosed large abdominal aortic aneurysm & 1 & 3.3 \\
Thoraco-abdominal aortic aneurysm & 2 & 6.7 \\
\hline
\end{tabular}

There were $63.3 \%$ of the studied cases had normal mesenteric artery by CT. Most common abnormalities founded among the studied cases were superior mesenteric artery occlusion, superior mesenteric artery stenosis and celiac artery stenosis (20\%, 10\% \& 10\% respectively) (Table 5).

Table (5): Mesenteric arteries abnormalities by CT among the studied cases

\begin{tabular}{|l|c|c|}
\hline \multirow{2}{*}{ Variable } & \multicolumn{2}{|c|}{$(\mathbf{n}=30)$} \\
\cline { 2 - 3 } & No & $\%$ \\
\hline CT: & & \\
Normal & 19 & 63.3 \\
Abnormal & 11 & 36.7 \\
\hline Superior mesenteric artery occlusion & 6 & 20 \\
Superior mesenteric artery stenosis & 3 & 10 \\
Celiac artery stenosis & 3 & 10 \\
Celiac artery occlusion & 2 & 6.7 \\
Superior mesenteric artery aneurysm & 1 & 3.3 \\
Superior mesenteric artery psudoaneurysm & 1 & 3.3 \\
Superior mesenteric artery calcified plaques & 1 & 3.3 \\
\hline
\end{tabular}

There was a statistical significance increase in frequency of vomiting among abnormal cases compared to normal (Table 6). 
Table (6): Comparison between normal and abnormal cases by mesenteric vein CT in age, sex and complain

\begin{tabular}{|c|c|c|c|c|c|}
\hline $\begin{array}{ll}\text { Parameters } & \text { Groups } \\
\end{array}$ & \multicolumn{2}{|c|}{$\begin{array}{c}\text { Normal } \\
(n=25)\end{array}$} & \multicolumn{2}{|c|}{$\begin{array}{c}\text { Abnormal } \\
(n=5)\end{array}$} & $\mathbf{P}$ \\
\hline $\begin{array}{l}\text { Age: }(\text { year }) \\
\text { Mean } \pm \text { SD } \\
\text { Range }\end{array}$ & \multicolumn{2}{|c|}{$\begin{array}{c}52.92 \pm 12.42 \\
33-81\end{array}$} & \multicolumn{2}{|c|}{$\begin{array}{c}48.6 \pm 9.07 \\
35-57\end{array}$} & 0.47 \\
\hline & $\mathbf{N}$ & $\%$ & $\mathbf{N}$ & $\%$ & $\mathbf{P}$ \\
\hline $\begin{array}{l}\text { Sex: } \\
\text { Male } \\
\text { Female } \\
\end{array}$ & $\begin{array}{l}17 \\
8\end{array}$ & $\begin{array}{l}68 \\
32 \\
\end{array}$ & $\begin{array}{l}5 \\
\mathbf{0}\end{array}$ & $\begin{array}{c}100 \\
0\end{array}$ & 0.14 \\
\hline $\begin{array}{l}\text { Complain: } \\
\text { Abdominal pain } \\
\text { Diarrhea } \\
\text { Vomiting } \\
\text { Loss of weight } \\
\text { Distension } \\
\text { Epigastria pain } \\
\text { Melena } \\
\text { Failed to pass stool } \\
\text { Dyspepsia } \\
\text { Fatigue }\end{array}$ & $\begin{array}{c}23 \\
10 \\
6 \\
8 \\
2 \\
2 \\
2 \\
2 \\
1 \\
1\end{array}$ & $\begin{array}{c}92 \\
40 \\
24 \\
32 \\
8 \\
8 \\
8 \\
8 \\
4 \\
4\end{array}$ & $\begin{array}{l}5 \\
2 \\
5 \\
0 \\
2 \\
0 \\
0 \\
0 \\
0 \\
0\end{array}$ & $\begin{array}{c}100 \\
40 \\
100 \\
0 \\
40 \\
0 \\
0 \\
0 \\
0 \\
0\end{array}$ & $\begin{array}{c}0.51 \\
1 \mathrm{NS} \\
0.001 \\
0.14 \\
0.06 \\
0.51 \\
0.51 \\
0.51 \\
0.65 \\
0.65\end{array}$ \\
\hline
\end{tabular}

SD: Standard deviation, t: independent $\mathrm{t}$ test, $\chi 2$ : Chi square test.

There was no statistical significance difference between normal and abnormal cases in age sex or complain (Table 7).

Table (7): Comparison between normal and abnormal cases by aortic artery CT in age, sex and complain

\begin{tabular}{|c|c|c|c|c|c|}
\hline $\begin{array}{ll}\text { Parameters } & \text { Groups } \\
\end{array}$ & \multicolumn{2}{|c|}{$\begin{array}{c}\text { Normal } \\
(n=22)\end{array}$} & \multicolumn{2}{|c|}{$\begin{array}{c}\text { Abnormal } \\
(\mathbf{n}=8)\end{array}$} & $\mathbf{P}$ \\
\hline $\begin{array}{l}\text { Age: }(\text { year }) \\
\text { Mean } \pm \text { SD } \\
\text { Range }\end{array}$ & \multicolumn{2}{|c|}{$\begin{array}{c}51.27 \pm 11.73 \\
33-81\end{array}$} & \multicolumn{2}{|c|}{$\begin{array}{l}54.75 \pm 12.8 \\
40-72\end{array}$} & 0.49 \\
\hline & $\mathbf{N}$ & $\%$ & $\mathbf{N}$ & $\%$ & $\mathbf{P}$ \\
\hline $\begin{array}{l}\text { Sex: } \\
\text { Male } \\
\text { Female }\end{array}$ & $\begin{array}{c}17 \\
5\end{array}$ & $\begin{array}{l}77.3 \\
22.7\end{array}$ & $\begin{array}{l}5 \\
3\end{array}$ & $\begin{array}{l}62.5 \\
37.5\end{array}$ & 0.42 \\
\hline Complain: & & & & & \\
\hline Abdominal pain & 20 & 90.9 & 8 & 100 & 0.38 \\
\hline Diarrhea & 9 & 40.9 & 3 & 37.5 & 0.87 \\
\hline Vomiting & 8 & 36.4 & 3 & 37.5 & 0.95 \\
\hline Loss of weight & 7 & 31.8 & 1 & 12.5 & 0.29 \\
\hline Distension & 3 & 13.6 & 1 & 12.5 & 0.94 \\
\hline Epigastria pain & 2 & 9.1 & $\mathbf{0}$ & $\mathbf{0}$ & 0.38 \\
\hline Melena & 1 & 4.5 & 1 & 12.5 & 0.44 \\
\hline Failed to pass stool & 2 & 9.1 & $\mathbf{0}$ & $\mathbf{0}$ & 0.38 \\
\hline Dyspepsia & 1 & 4.5 & $\mathbf{0}$ & $\mathbf{0}$ & 0.54 \\
\hline Fatigue & 1 & 4.5 & $\mathbf{0}$ & $\mathbf{0}$ & 0.54 \\
\hline
\end{tabular}

SD: Standard deviation, $\mathrm{t}$ : independent $\mathrm{t}$ test, $\chi 2$ : Chi square test 


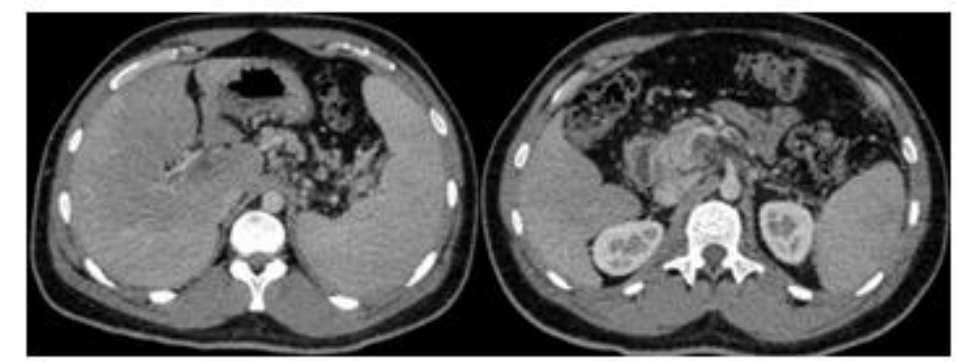

Figure (1): A 35years old, male patient, referred with acute colicky abdominal pain, distension, vomiting,axial CT cuts showed superior mesenteric and portal vein thrombosis

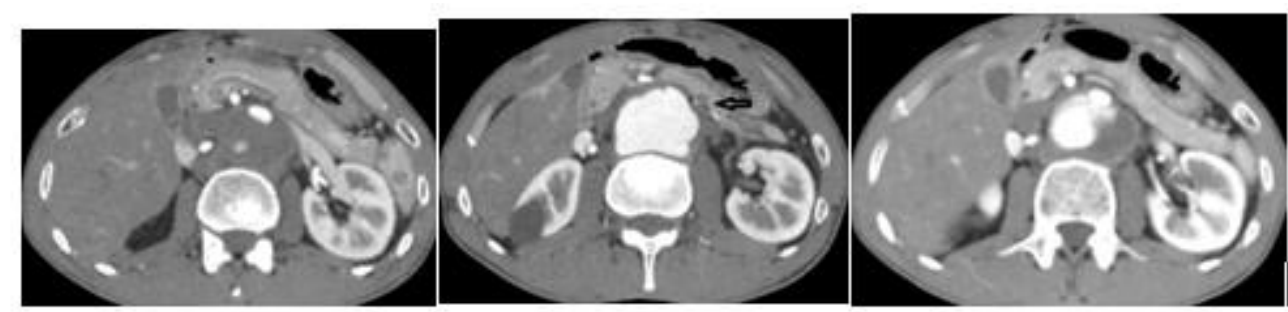

Figure (2): A 44 years old,male patient, referred with acute abdominal pain, vomiting axial CT cutsshowed thrombosed aortic aneurysm and superior mesenteric, splenic and inferior mesenteric veins thrombosis

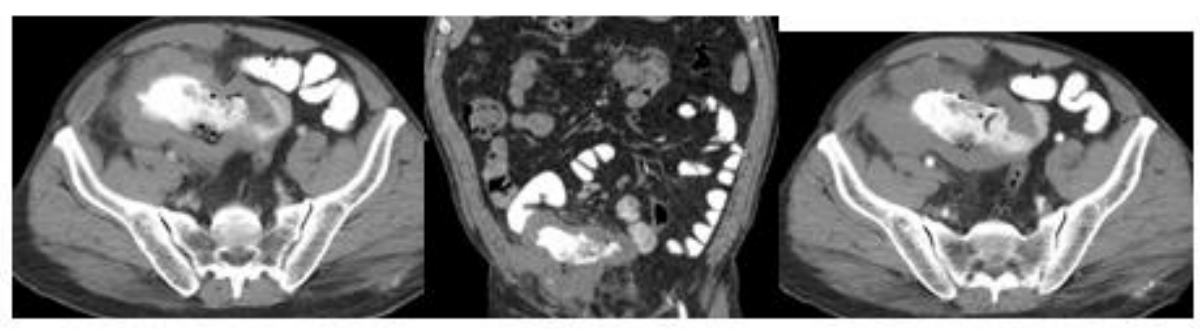

Figure (3): A male patient, 47 years old, referred with chronic diarrhea, loss of weight and recurrent abdominal pain,axial and coronal CT cuts showed marked diffuse circumferential wall thickening of the terminal ilium with aneurysmal dilatation of its lumen
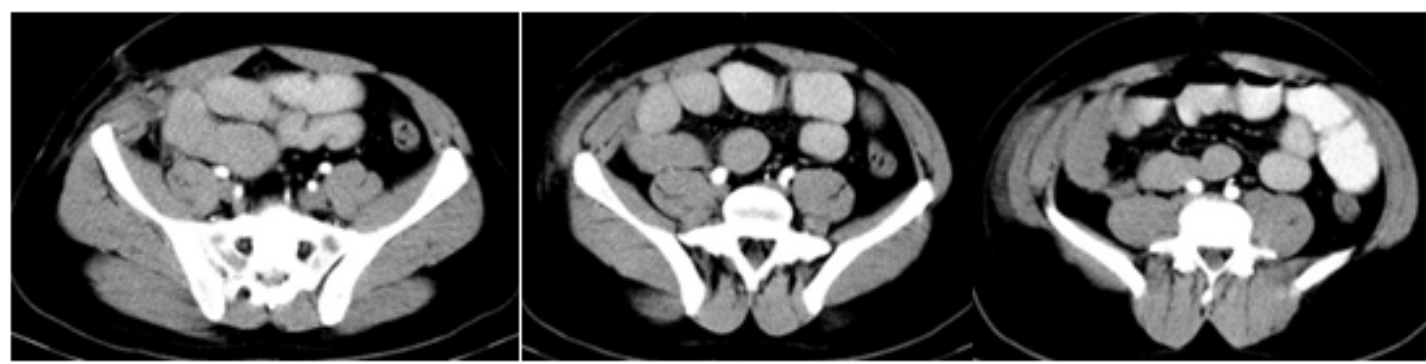

Figure (4): A 42 years old, male patient, referred with abdominal pain, failed to pass stool, axial CT showedIntestinal obstruction, scar of previous operation (adhesive obstruction) 


\section{DISCUSSION}

Multi-detector computed tomography (MDCT) is a relatively new imaging technique that combines the improved spatial and temporal resolution of MDCT with large amounts of ingested neutral contrast material. CT enterography uses neutral oral contrast material as water combined with mannitol, allowing bowel distention and detection of the abnormal mucosal enhancement Unlike routine CT, which uses high-density oral contrast material, (Afifi and Kassem, 2012).

The present study focused on the use of MDCT enterographyand angiography for the diagnosis of small bowel diseases. The patients suspected clinically to have small bowel disease were included in. The main presenting symptoms were abdominal pain, vomiting and constipation.

Some patients had vascular diseases, others had intestinal obstruction, others had inflammatory diseases, and others had neoplastic diseases and one patient showed mesenteric panniculitis. These results approved with Sinha (2018) who stated that, MDCT is becoming the firstline modality for the evaluation of suspected inflammatory bowel disease, and also became an important alternative to barium follow through in the assessment of other small bowel disorders such as small bowel neoplasms.

Elsayes et al (2010) used a bolus of intravenous contrast material $(125 \mathrm{ml}$, Isovue $370 \mathrm{mgI} / \mathrm{ml}$ ) followed by $50 \mathrm{ml}$ of saline solution is administered with a power injector at a rate of $4 \mathrm{ml} / \mathrm{sec}$. Begin the acquisition 65 seconds after the administration of intravenous contrast material.
AfifiandKassem (2012) stated that CT enterography has the ability to show subtle findings in Crohn's disease such as mucosal hyper vascularity or mild wall thickening, which are not showed by standard barium examinations. Also, evaluation of the surrounding mesenteric fat planes for stranding and fat proliferations and the assessment of enlarged draining lymph nodes are evaluated superiorly with CT enterography, which was approved with our study.

In this study, it was found that the most common clinical presentation of the inflammatory bowel disease especially Crohn's disease was the abdominal pain. Mohamed et al. (2012) reported also that Crohn's disease frequently manifested by abdominal pain, but it is often not clear whether this pain is caused by active inflammation, by stenosis and proximal dilation, or both.

In this study, it was found that the most frequent MSCT finding in patients with inflammatory lesions was the bowel wall thickening and enhancement found in 7 patients (100\%).Bowel wall enhancement was present in almost cases (86.7). Mohamed et al. (2012) reported also bowel wall enhancement was present in almost all cases $(96 \%)$.

The present study used the bi-phase scanning (Mesenteric CT angiography) in patients who were suspected to have bowel ischemia either due to mesenteric vascular occlusion or mechanical intestinal obstruction. It was found that the most common cause of mesenteric ischemia was the superior mesenteric artery occlusion found in $(54.54 \%)$ of patients. The most frequent MSCT finding 
with mesenteric ischemia was the bowel wall thickening found in $(71.4 \%)$ of patients.

In agreement with this study, $A l-A z z a z y$ et al (2012) reported that the most common finding of mesenteric ischemia regarding the intestine was mural bowel wall thickening $(89.2 \%)$.

In this study, it was found that the most frequent CTA finding with acute mesenteric ischemia in the current study was the portal and superior mesenteric venous thrombosis found in 4/6 (66.6\%). However, Al-Azzazy et al (2012) reported that the arterial thrombo-embolic cause was the most common in AMI (75\%). This may be due to decreased number of AMI patients due to the rapid surgical interference.

In this study, it was found that the CTA finding with chronic mesenteric ischemia in the current study was the arterial atherosclerosis causing arterial stenosis defined as luminal narrowing of $>50 \%$. In agreement with the results of this study, Al-Azzazy et al. (2012) reported that systemic atherosclerosis causing arterial stenosis was the most common cause of the CMI cases. Terlouw et al. (2020) stated that intestinal obstruction is a common occurrence with superiority of $\mathrm{CT}$ in revealing the site, level and cause of obstruction and in demonstrating threatening signs of bowel in viability. CT has proved useful in characterizing bowel obstruction from extrinsic causes (adhesions, closed loop obstruction, strangulation, hernia), extrinsic masses, intrinsic causes (adenocarcinoma, Crohn's disease, tuberculosis, radiation enteropathy, intramural hemorrhage and intussusception), intraluminal causes (e.g., bezoars) or intestinal malrotation. Conventional radiography was the modality of choice for many years and should remain the initial imaging method in patients with suspected small bowel obstruction. However, the unique capabilities of CT in this setting make this modality an important diagnostic tool. Ilangovan et al (2012) found that CT enterography is a preferred technique over CT enteroclysis although the superior jejunal distention attained using enteroclysis because of the convenience, efficiency and superior patient experience achieved with CT enterography.

\section{CONCLUSION}

MDCT is the first-line modality for the evaluation of suspected inflammatory bowel disease and also became an important alternative to barium follow through in the assessment of other small bowel disorders such as small bowel neoplasms and mesenteric ischemia.

\section{REFERENCES}

1. Afifi AH. andKassem, MI. (2012): Crohn's disease: Activity, complications and treatment. Evaluation using MDCT enterography and endoscopy. The Egyptian Journal of Radiology and Nuclear Medicine, 43: 507-517.

2. Al-Azzazy MZ; Hasan, DI; ElSherbeni, ME. andGameel, AM. (2012): Multi detector CT and CT angiography in mesenteric ischemia. The Egyptian Journal of Radiology and Nuclear Medicine, 43: 337-345.

3. Chuong A. M.; Corno L., Beaussier H., Boulay-Coletta I., Millet I., Hodel J., and Zins M. (2016): Assessment of bowel wall enhancement for the diagnosis of intestinal ischemia in patients with small bowel obstruction: value of adding 
unenhanced CT to contrast-enhanced CT. Radiology, 280(1): 98-107.

4. Elsayes KM.; Alhawary MM. and Jagdish J. (2010): CT Enterography: principles, trends, and interpretation of findings. Radiographics, 30: 1955-1970.

5. Ilangovan R.; Burling D. and Gupta A. (2012): CT enterography: review of technique and practical tips. The British Journal of Radiology, 85: 879-886.

6. Kanasaki S.; Furukawa, A., Fumoto, K., Hamanaka, Y., Ota, S., Hirose, T., and Tulyeubai, S. (2018): Acute mesenteric ischemia: multidetector CT findings and endovascular management. Radiographics, 38(3): 945-961.

7. Mohamed AM; Amin, SK and ElShinnawy, MA (2012): Role of CT enterography in assessment of Crohn's disease activity: Correlation with histopathologic diagnosis. The Egyptian Journal of Radiology and Nuclear Medicine, 43: 353-359.
8. Postema, M. and and Gilja, O. H. (2011): Contrast-enhanced and targeted ultrasound. World Journal of Gastroenterology: WJG, 17(1); 28.

9. Rengo M.; Picchia S. and Laghi A. (2017): Introduction, Small Bowel MDCT, Med RadiolDiagn Imaging, Springer International Publishing AG, In Multislice CT (pp. 619-639). Springer, Cham.

10. Sinha, R. (2018): Intestinal imaging: the last frontier. J GastrointestAbdomRadiol, 1(1), 7-11.

11. Terlouw, L. G., Moelker, A., Abrahamsen, J., Acosta, S., Bakker, O. J., Baumgartner, I., and Bruno, M. J. (2020): European guidelines on chronic mesenteric ischaemia-joint United European Gastroenterology Journal, 8(4), 371-395. 


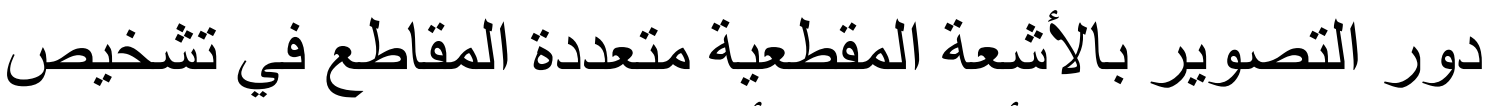

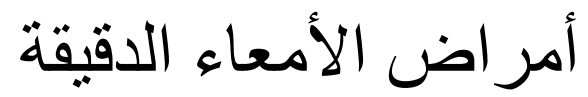

سارة السيد جوده محمد، محمد فاروق عجاج، عبد الله حسين أحمد

قسم الأثعة التثخيصية، كلية الطب، جامعة الأزهر

E-mail: $\underline{\text { sosoo.sarah@yahoo.com }}$

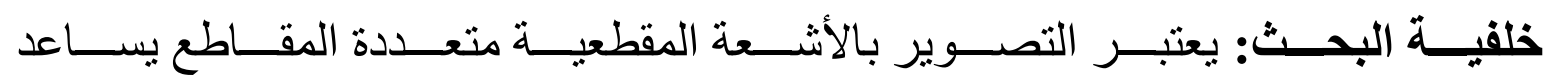

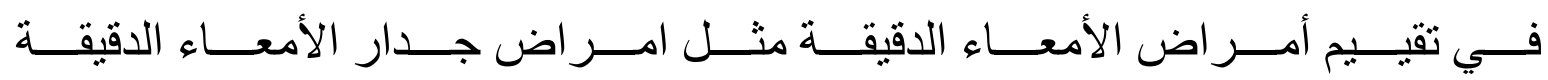

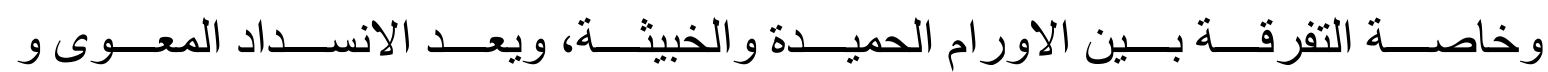

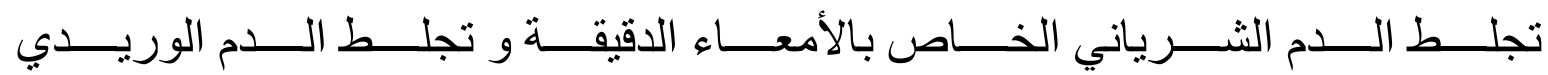

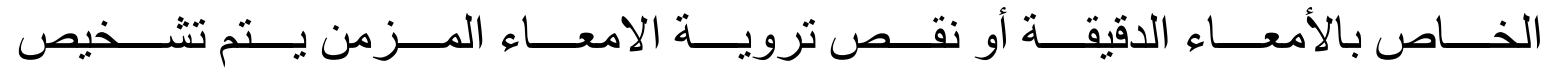
ذلك بالأشعة المقطعية متعددة المقاطع.

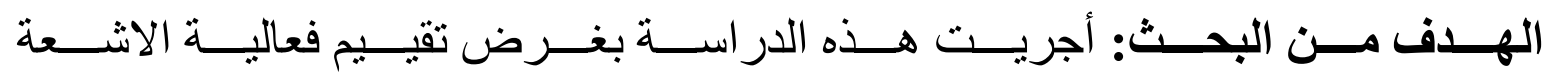

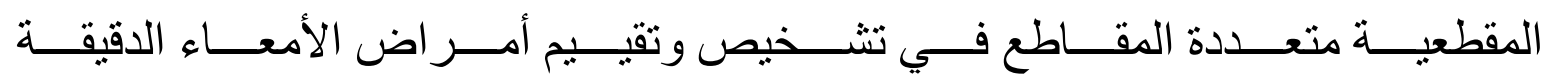

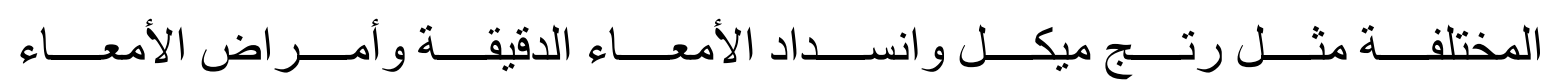
الالتهابية ونقص تروية الأمعاء.

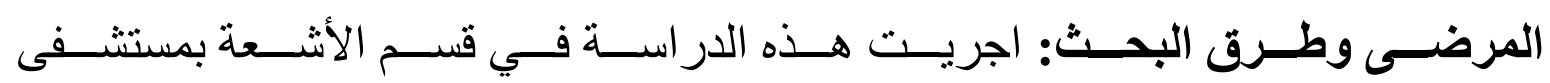

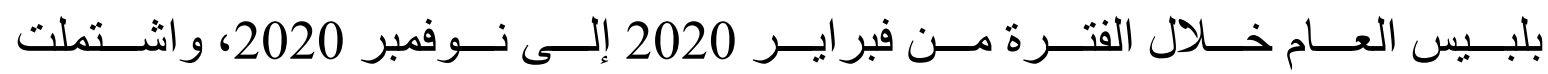
علــ30 مريضـاً: 22 مـن الــذكور و 8 مــن الإنــاث، يعـانون مــن آلام الـبطن

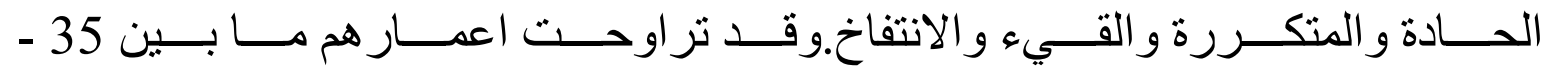
81 سنة بمتوسط اعمار 59.35 سنة.

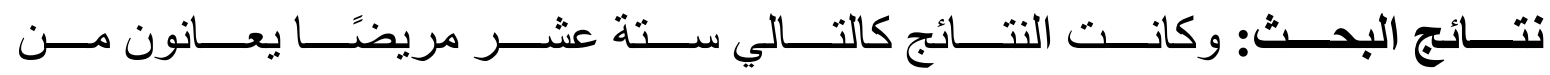

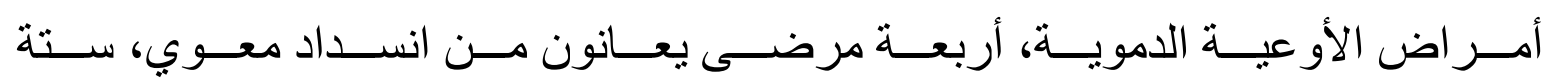




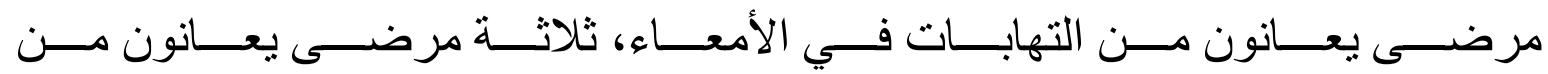
مرض الأورام وأظهر مريض واحد التهاب السبلة الثحمية المساريقية.

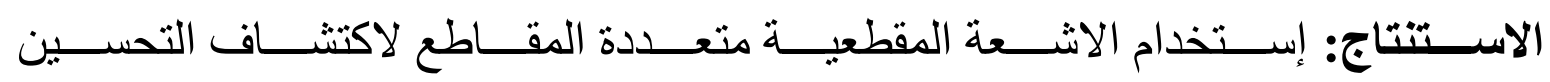

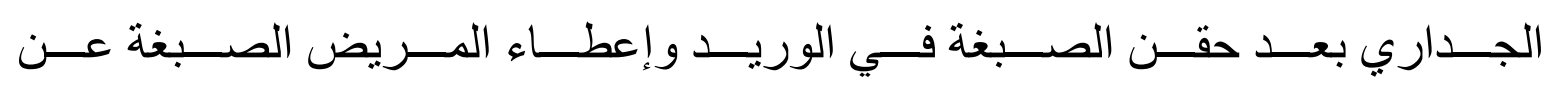

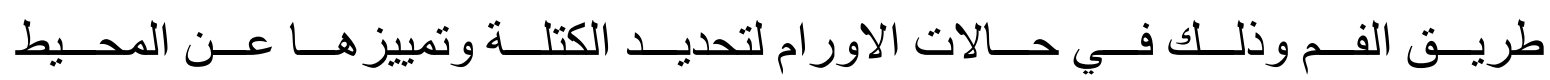

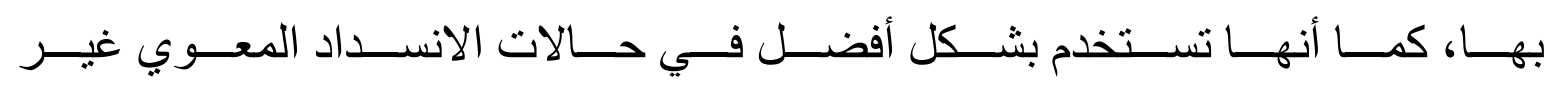

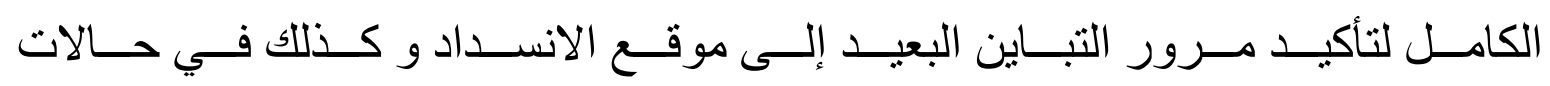
نقص الترويه للامعاء.

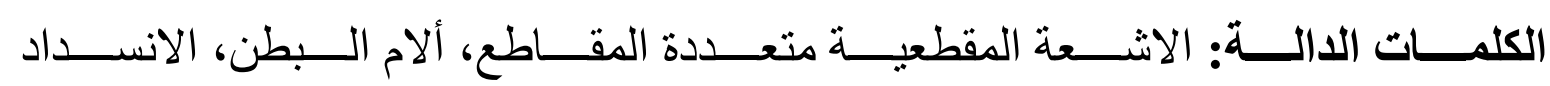
المعوى، سماكة جدار الأمعاء، أمر اض الأوعية الدموية. 